\title{
Research on the Construction of Tea Marketing Information Service Platform of Shaanxi Province Under the Background of "Internet +"
}

\author{
Wei Sun * \\ School of Electronic Information Engineering \\ Xijing University \\ Xi'an Shaanxi, China
}

\author{
Mengjia Yao, Mengjing Wang, Fan Yu \\ Wanjun Academy \\ Xijing University \\ Xi'an Shaanxi, China
}

\begin{abstract}
The necessity of the construction of Shaanxi tea marketing service platform is analyzed by the SWOT method in the paper. The purpose of the work is to design the overall framework of the "Internet + tea products" marketing service system guarantee platform. Relying on the network platform provided by the Internet, it can promote the informatization of traditional tea production, operation, and management. It can also improve the competitiveness of modern tea farmers in Shaanxi Province.
\end{abstract}

Keywords-Tea Marketing; Information Platform; Internet +; SWOT Method

\section{INTRODUCTION}

"Internet + " can promote the transformation and upgrading of the industrial economy and accumulate a new pattern of economic development [1]. In the "Internet $+"$ era, with accurate information acquisition, accurate data analysis, and other favorable conditions, information and communication technology can be effectively integrated to realize the digitization and visualization of tea logistics information. The integration can make the layout of the tea industry more reasonable; meanwhile, tea farmers can obtain targeted information and services more conveniently.

Compared to the developed provinces in the east, Shaanxi province is located in the northwest with a relatively underdeveloped economy. The development level of different parts of the province varies greatly. Some new rural network infrastructure is insufficient and communication facilities are still weak [2-3]. Most tea producing areas in Shaanxi province are in mountainous areas. The people who are in the tea marketing industry are uneducated, which means it is harder for them to acquire and absorb professional knowledge and novel technology. Therefore, it is urgent to build an information-based service platform for tea marketing.

"Internet+" is a new open model based on platforms and interfaces. "Internet + " Shaanxi tea marketing information service platform plays an information bridge among the tea industry chain of agricultural products. Through accumulation, storage, analysis and other integration of the tea industry chain of scientific and technological, logistics, and financial resources, "Internet + " can provide accurate services for agriculture-related subjects.

\section{SWOT STYLING ANALYSIS OF "INTERNET + " TEA MARKETING IN SHAANXI PROVINCE}

Advantage: As the core province of northwest China, Shaanxi has unique geographical advantages and good transportation conditions to help the marketing of tea. "Internet $+"$ can change the traditional marketing mode, and the internetbased logistics mode can make tea products reach consumers quickly, so as to ensure the freshness and quality of tea products. In the "Internet + " mode tea farmers can cooperate with e-commerce platforms to sell tea products directly to consumers and break the price monopoly of intermediaries. Modern technology can also promote the mechanization of tea processing, product diversification; increase the size of tea, tea processing to packaging forming an assembly line.

Disadvantage: In order to timely control the situation of tea market information logistics link; the whole sales chain of tea products needs the support of highly accurate information technology. Compared with the developed areas in the east, the overall level of Shaanxi logistics information platform is lower, and the systematization degree of product logistics information platform still needs to be provided, without overall planning [4]. In the era of "Internet + ", there is a great demand for compound talents who are proficient in Internet technology and agricultural knowledge. Most ordinary farmers are engaged in production and processing based on their personal experience. The penetration rate of Internet broadband in remote mountainous areas of Shaanxi needs to be further improved.

Opportunity: Issues concerning agriculture, rural areas and farmers are the focus of the work of the party and the state. The new generation of IT technology has also been applied in the production and marketing of agricultural products.

Threat: A certain degree of social prejudice against agriculture causes young talents to be unwilling to engage in agriculture-related work. There is a shortage of compound talents who master Internet information and agricultural production technology. At present, the application of rural information technology lags behind cities by $44 \%$, presenting a weak distribution pattern in the central and western regions and the east [5]. There are high costs such as GPS, GIS system. 
their needs for tea. After-sales system: to get feedback from the system is of great significance to improve product quality. Establish a quality traceability system in the sales of tea products. By scanning the code, consumers can obtain product information; improve the quality supervision of tea source and consumer satisfaction. production base is located in Shangnan county in the shallow mountain belt of Qinling mountains. Meanwhile, the brand of black tea is Jingyang Fuzhuan tea. Despite the ecological superiority of Hanzhong, Ankang and Shangluo tea areas in southern Shaanxi. The tea is not well known and its embarrassing situation is not commensurate with its status and influence in history.

The new economic information with the Internet as the core has brought new opportunities and challenges for the production and sales of Shaanxi tea. Through the internet platform to provide technical support for the intelligent marketing of tea, production, sales, logistics and management comprehensive integration.

\section{BUILDING "INTERNET + TEA PRODUCTS" MARKETING INFORMATION PLATFORM}

According to the production status of Shaanxi tea production area and the status of Internet technology, develop the "Internet + " marketing mode and functional design of Shaanxi tea.

For the tea industry chain links, the function of the platform is divided into tea product cycle based on the transportation system, sales system and after-sales system, and the marketing information platform of "Internet + tea products" is constructed. Apply the advanced technology of Internet into the production, operation and sales system of tea products. To provide a comprehensive network marketing model for the sale of tea products. Improve the competitiveness and added value of Shaanxi tea products, to increase the income of tea farmers' entrepreneurship.

The marketing platform of "Internet + tea products" is systematic, consumer-centered and feasible. In the Internet era, big data is used to analyze consumers' consumption demands, providing producers with channels to understand and collect consumers, and providing consumers with better services. Combined with the current situation of local tea production and the development level of Internet technology, it is necessary to develop the network marketing mode of agricultural products according to local conditions.

The production and sales of tea products have provided an opportunity in the Internet era. Marketing system is a systematic project. Internet technology runs through the whole production and sales cycle of "production-transport-sales-aftersale" of tea products. Fig. 1 shows the pattern of production and sales cycle of tea products.

Production system: to solve the imbalance between supply and demand of tea products, tea producers forecast the future consumption trend through the data and information of consumers. Transportation system: the transportation process is directly related to the quality and sales price of tea products. Sales system: with the characteristics of cross-regional space of the Internet, provide accurate services for consumers to meet

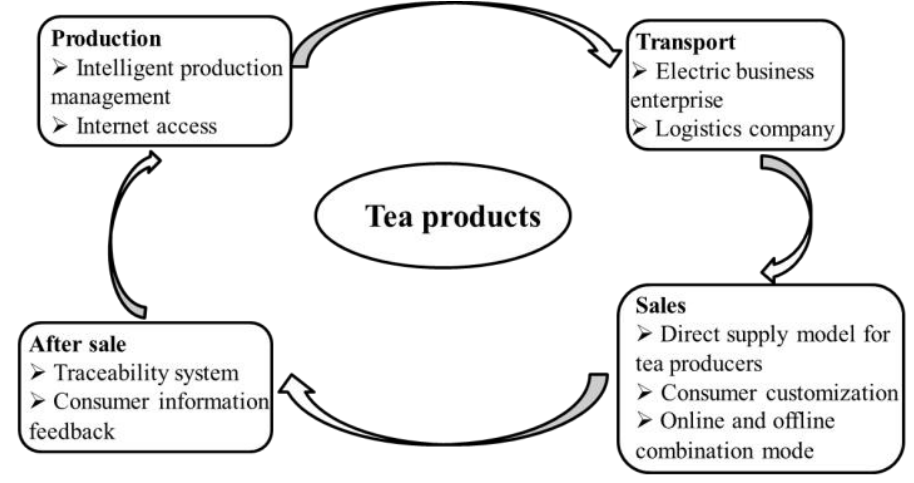

Fig. 1. Pattern of production and sales cycle of tea products

"Internet + tea product" marketing system is system engineering. The marketing information platform can expand the extension scope of tea farmers, achieve the optimal sales channel, and achieve a reasonable transaction price. This platform should be built in a systematic, consumer-centered and feasible way. In the Internet era, big data is used to analyze the psychological characteristics and consumption demands of consumers, so as to provide producers with channels to understand consumer information and provide consumers with high-quality and satisfactory products and services. It is necessary to formulate the agricultural product network marketing mode "according to local conditions" according to the production status of local tea products and the development level of Internet technology. The integrated information platform of "tea marketing" is shown in Fig. 2, which realizes the function platform integrating e-commerce logistics, financial risk monitoring and tea merchants and consumers.

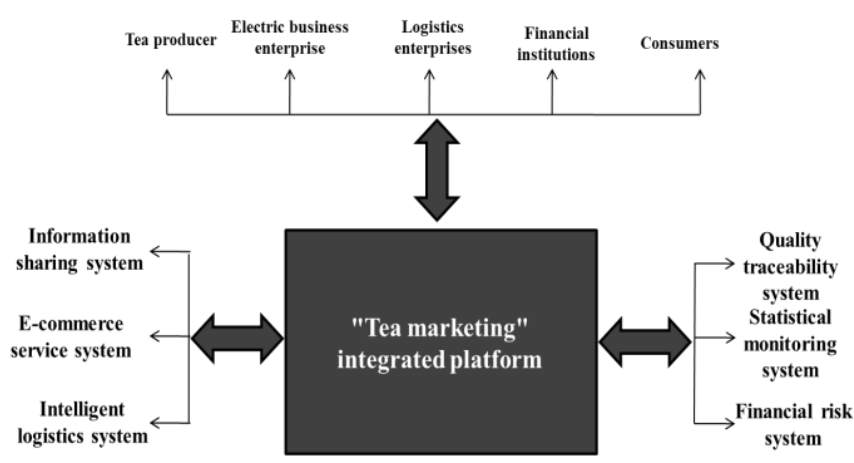

Fig. 2. Integrated information platform of "tea marketing"

The producers and operators obtain the market, quality production industry through the network information, and realize the traceability of tea marketing. management, capital law and other related resources of the 


\section{IV. "INTERNET + TEA PRODUCT" MARKETING SERVICE SYSTEM GUARANTEE PLATFORM}

The information service platform integrates the Internet and the tea industry. The platform makes use of information flow to break through and control the industrial chain, realizing the "match between supply and demand" and the integration of production, supply and marketing. It plays the role of the information bridge in the tea industry chain. Starting from the connection between supply and demand, it organically integrates the scientific and technological resources, logistics resources and financial resources of the agricultural industry chain through information accumulation, storage and analysis to provide precise services for tea marketing. Under the trend of "Internet +", it is also necessary to build a guaranteed platform for information-based marketing service system, as shown in Fig. 3. Guide product circulation participants to conduct publicity, sales and personnel training with the help of online platforms.

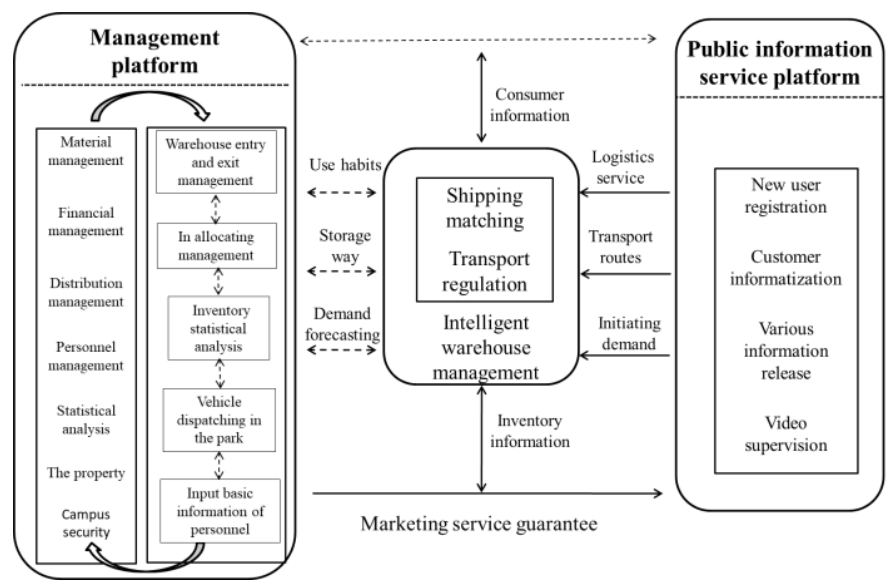

Fig. 3. The guarantee platform of marketing service system

Producers and operators obtain first-hand production technology and industry market information resources through the Internet. The application service layer contains service modules and functions of the platform. Users can achieve their goals by accessing and operating the system. By breaking down the features, the platform can quickly meet the constantly updated and diversified business needs. It can provide a new development model for the rapid development of Shaanxi tea industry chain by relying on the technical support and platform provided by the Internet.
The business of the management platform includes physical management, personnel management, accounting management, distribution management, statistical analysis, park property management, park security and other integrated management modules. Its functions include warehousing and outbound management, allocation management, inventory statistics and analysis, vehicle scheduling in the park, and basic information entry of personnel, etc. Information sharing can be realized among various functions, so as to realize interconnectivity within the system, further integrate park resources, and improve the overall material turnover rate.

\section{CONCLUSION}

This paper adopts SWOT method to analyze the current situation and development strategy of Shaanxi tea marketing from the perspective of industry and region. The production and marketing cycle model of tea products is given. The marketing information platform of "Internet + tea product" is constructed. The design framework of an information-based marketing service system guarantee platform is completed, and the design of information flow, capital flow, and goods flow are accomplished. Tea marketing platform has achieved informatization and big data, which can quickly change the information lag phenomenon in traditional tea marketing. It can promote traditional tea production, management mode of rapid innovation and improve the competitiveness of modern tea farmers in Shaanxi province.

\section{REFERENCES}

[1] H. T. Ma. "Suggestions on promoting the innovative development of China's economy and society driven by Internet plus", China Science and Technology Industry, 2016, vol.3, pp.38-39. (In Chinese)

[2] F. Wang. "Exploring the path of brand construction of Shaanxi tea", China Agricultural Information, 2016, vol.9, pp.157-159. (In Chinese)

[3] Y. Ju. Exploration on transformation and upgrading of tea industry in Shaanxi province, Xi'an: Northwest Agricultural and Forestry University, 2017. (In Chinese)

[4] L.P. Meng. "Countermeasures of Internet plus modern agriculture in Shaanxi", Acta Agriculica Jiangxi, 2018, vol.7, pp.141-145. (In Chinese)

[5] H. Y. Liang, C.S. Li. "Why does the floating population wander in the countryside and the city?" Population and Development, 2015, vol. 21, pp.32-40. (In Chinese)

[6] M. Young. The Technical Writer's Handbook. Mill Valley, CA: University Science, 1989. 